\title{
Controlling puff volume without disrupting smoking topography
}

\author{
EDWARD D. LEVIN, JED E. ROSE, and FREDERIQUE BEHM \\ Veterans Administration Medical Center, Brentwood, Los Angeles, California
}

\begin{abstract}
In studies of the behavioral and physiological effects of cigarette smoking, it is of critical importance to keep the dose of nicotine as constant as possible. This is difficult with smoking, because when the nicotine delivery of a cigarette is increased or reduced, smokers tend to compensate by modifying their smoke intake. In a laboratory study, it is relatively easy to control the number of cigarettes and the number of puffs taken, but it is more difficult to control the volume of each puff. Various procedures have been developed to control puff volume, but they have a disadvantage of disrupting the normal topography of smoking. We have developed an apparatus for delivering fixed volumes of smoke that has given consistent tar and nicotine values needed in studies of the behavioral and physiological effects of cigarette smoking. This method has the distinct advantage of allowing the subject to inhale the smoke in a normal fashion, with a draw resistance comparable to that of a cigarette. The device is inexpensive and easy to make.
\end{abstract}

In any pharmacological study, it is of crucial importance to have control over the dose of drug given to the subject. Usually, the experimenter achieves this control by carefully administering a specified amount of the drug. However, it becomes more of a problem when the drug is self-administered. This problem is particularly difficult with cigarette smoking, because there are many ways in which the subject can adjust the dose of total smoke inhaled. A variety of studies have demonstrated that when the nicotine level of a cigarette is reduced, smokers tend to increase their intake to compensate for the lowered nicotine concentration (Adams, 1978; Creighton \& Lewis, 1978; Dunn, 1978; Gust and Pickens, 1982; Henningfield \& Griffiths, 1980; Herning, Jones, Bachman, \& Mines, 1981; Rawbone, 1981; Rawbone, Murphy, Tate, \& Kane, 1978; Stepney, 1980; Sutton, Feyerbend, Cole, \& Russell, 1978). The smoker can adjust either the number of cigarettes smoked, the number of puffs taken per cigarette, the puff volume, or the depth and duration of inhalation to alter the amount of nicotine delivered (Herning, Jones, Benowitz, \& Mines, 1983). This adjustment in smoking behavior would work to attenuate the effects of experimental manipulations of nicotine dose.

In a laboratory study, it is relatively easy to control most of these variables. The experimenter can control the number cigarettes smoked and instruct the subject on the number of puffs to be taken and the length of time each puff is to be held in the lungs. Importantly, the experimenter can verify that the instructions are followed. However, one crucial means of adjusting smoke intake, changing

This work was supported by a grant from the John D. and Catherine T. MacArthur Foundation, Grant DA 02665 from the National Institute on Drug Abuse, and the Medical Research Service of the Veterans Administration. Correspondence may be sent to Edward D. Levin, Nicotine Research Lab, 691/B151N, VA Medical Center, Brentwood, Los Angeles, CA 90073. the volume of each puff, has proven to be difficult to control.

One approach for controlling puff volume is to draw smoke from a cigarette using a syringe, inject it into a holding container, and have the subject inhale the smoke, followed by a measured volume of air from a breathing bag (Rose, Tashkin, Ertle, Zinzer, \& Lafer, 1985). Although this method achieves the goal of delivering a constant amount of smoke, it has several drawbacks. One problem is that there is inevitably some deposition of smoke particles on the inner surface of the syringe and container. Thus, the smoke may lose some of its strength in the process of transfer.

Additionally, during the time the smoke resides in the syringe and holding container, the particles in the smoke tend to coalesce, resulting in greater particle size and altered distribution in the respiratory tract (Raabe, 1980). With aerosols used to simulate smoke (Behm, Levin, Lee, \& Rose, 1989; Rose \& Behm, 1987; Rose \& Hickman, 1987), which may have substantially greater particle sizes, these losses can be considerable. Another problem with this method is the disruption of puff topography by the elimination of draw resistance. Usually, cigarette smoking involves a two-stage process in which smoke is initially drawn into the mouth against the resistance of the cigarette and then inhaled into the lungs. Drawing smoke from a holding bag disrupts this process and may cause abnormal reactions because of differing motor and sensory aspects of the smoking experience.

Variations of this method (e.g., smoke is injected from a syringe directly into the subject's mouth) have been been tested and found to yield control over nicotine delivery (Gilbert, Jensen, \& Meliska, 1988; Pomerleau, Rose, Pomerleau, \& Majchrzak, 1989). However, the problem remains of artificiality introduced by the absence of draw resistance. Also, these methods are not suitable for aerosols consisting of large particles. 
Another approach in controlling puff volume is to use a pressure transducer and microcircuitry to calculate the volume of smoke inhaled and have a clamp close off a tube between the cigarette and the mouth. This method avoids problems of deposition and abnormal smoking topology inherent in the container method described above but is quite expensive and complicated to make. A related approach that trains subjects to regulate puff volume and inhalation depth in response to feedback cues from strain gauge and pressure transducers (Zacny, Stitzer, Brown, Yingling, \& Griffiths, 1987) is also somewhat complex and expensive.

We have developed an inexpensive method that presents the smoker with a constant volume of smoke to be inhaled. Instead of injecting it into the mouth of the subject, the smoker is allowed to puff normally and control the process of smoke intake. This method uses principles similar to those used in the puff-volume measuring device designed by Gust, Pickens, and Pechacek (1983).

\section{METHODS}

\section{Construction}

As shown in Figure 1, the device principally consists of two syringes: a plastic syringe, with the plunger re- moved, holds the cigarette, and a glass one serves as a reservoir of air. The filter end of the cigarette is placed in a cigarette holder mounted on the inner end of a onehole rubber stopper. Surrounding the cigarette are three rigid metal rods that guide the cigarette (as it is quickly inserted) straight into the plastic barrel and that prevent the lit end of the cigarette from coming into contact with the sides. These rods are inserted into the inner surface of the rubber stopper around the cigarette holder. They are fused to a metal ring beyond the distal end of the cigarette. A mouthpiece is connected to the outer end of the one-hole stopper. The volume of dead airspace between the cigarette and mouthpiece is $5 \mathrm{ml}$. Tygon tubing at the other end of the plastic syringe is attached to the bottom end of a $50-\mathrm{ml}$ glass syringe. A three-way valve allows air to be drawn into the glass syringe before each puff. All of the seals must be airtight, or an insufficient amount of smoke will be delivered.

\section{Operation}

First, the cigarette is placed into the cigarette holder and lit. The glass syringe is pulled back to the desired puff volume (in our studies, $35 \mathrm{cc}$ ). Just before the puff is to be taken, the rubber stopper with the cigarette is quickly inserted into the plastic syringe. The subject then

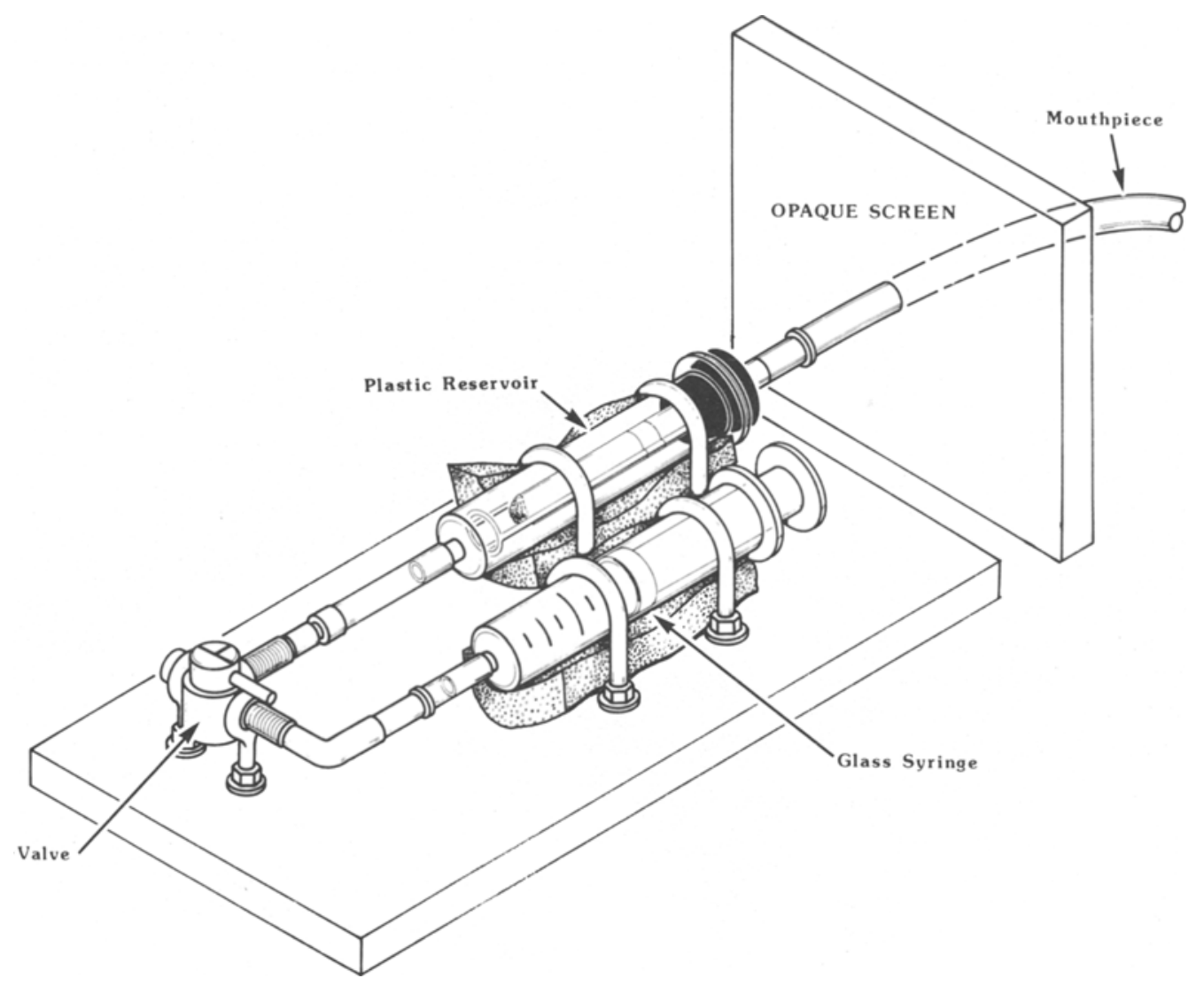

Figure 1. Diagram of the measured puffing apparatus. 
takes the puff from the mouthpiece. During the puff, the plunger of the glass syringe slides down the barrel to supply a measured quantity of air to the burning cigarette. The piston of the glass syringe moves freely along the barrel with little resistance. This adds very little to the total draw resistance. Between puffs, the cigarette is removed from the plastic barrel to keep it from extinguishing.

In our studies, nicotine deliveries of smoke puffed through the apparatus were measured by trapping the smoke particulates exiting the mouthpiece in a Cambridge filter. The filters were sent to the Clinical Psychopharmacology Laboratory at the Veterans Administration Medical Center (Sepulveda, CA) for tar and nicotine analyses. After extraction with methanol, samples were analyzed for tar, measuring the UV absorbance at $400 \mathrm{~nm}$ (Wu, Tashkin, Djahed, \& Rose, 1988), and nicotine was assayed using high pressure liquid chromatography (HPLC).

\section{RESULTS AND DISCUSSION}

We have found that this device is easy to use and economical to make. Calibrated syringes facilitate the dispensing of the desired volume of smoke. With this apparatus, the subjective experience closely resembles the natural act of smoking, with puff volume held constant. At the end of each puff, there is a necessary increase in draw resistance to the maximum so that the smoker cannot draw any more smoke and, thus, the puff volume is controlled. The subjects in our experiments recognized this abrupt increase in resistance as signaling the end of the puff, released their lips from the apparatus, and began inhaling room air as they normally would at the end of a puff from a cigarette.

Caution must be taken when using cigarettes low in tar and nicotine. If the tar and nicotine delivery depends on air flow through ventilation holes in the cigarette, the use of this apparatus may result in a considerably higher tar and nicotine delivery, because side stream smoke will be taken in through the ventilation holes. An equivalent dilution of smoke can be made under controlled conditions using a slight modification of the apparatus: a second syringe is attached to the mouthpiece, dispensing a measured quantity of air directly to the subject as the first syringe delivers a measured volume of smoke.

Our calibration tests of the device, using a commercial cigarette with reported deliveries of $1.0 \mathrm{mg}$ nicotine and $16 \mathrm{mg}$ tar, were $1.2 \pm 0.2 \mathrm{mg}$ nicotine and $17.7 \pm 2.9 \mathrm{mg}$ tar (mean \pm standard deviation) in 10 puffs, with a puff volume of $35 \mathrm{cc}$.

Crucial to the design is the control of puff volume with a fixed amount of air going into the cigarette. In preliminary designs, we tried controlling the volume of smoke taken from the cigarette by automatically clamping off the tube between the smoker's mouth and the cigarette when a measured amount of smoke had been drawn into the mouth. The problem with clamping off the intake from the cigarette is that, since the tube between the cigarette and mouth must be kept short to minimize the dead space, the clamping must be just in front of the smoker's lips. The closure of the clamp at such close range is fairly disconcerting to the subject. (It might work if the valve opened a bleed path so that air would enter.) A second preliminary attempt involved pulling smoke into a holding bag and allowing the subject to inhale the smoke from the bag. The problem with holding cigarette smoke in a bag is that, even with a brief duration, there is a substantial amount of deposition of the smoke inside the bag.

Our device, as presently configured, does not control the rate at which a puff is taken. This rate can be controlled, if the air syringe plunger is mechanically pushed down at a predetermined rate. This was not done in the version of the apparatus that we tested, because one of our main goals was to keep the act of smoking as naturalistic as possible. Also, we have found that changes in puff duration over the normal range seen in smokers have little effect on smoke delivery in this device. When a series of $1035 \mathrm{cc}$ puffs (one every $30 \mathrm{sec}$ ) was taken from a cigarette $(16 \mathrm{mg}$ tar and $1 \mathrm{mg}$ nicotine by the FTC method), an average of $13.5 \pm 2.8 \mathrm{mg}$ (mean \pm standard deviation) of tar was delivered with a 2 -sec puff, and an average of $15.6 \pm 0.2 \mathrm{mg}$ of tar was delivered with a 4-sec puff.

Depth of inhalation also was not controlled in our tests. The use of an airbag or spirometer (Rose et al., 1985; Pomerleau et al., 1989) would make it possible to combine puff volume control with inhalation volume control. However, Gilbert et al. (1988) have recently shown that the experimenter can ensure quantitative nicotine delivery simply by instructing subjects to inhale each puff deeply, with the mouth open, and verifying inhalation by watching for any smoke leaking from the subject's mouth. Manipulating puff volume while leaving inhalation volume uncontrolled could be a useful technique for studying compensatory changes in smoking in response to alterations of cigarette nicotine delivery. By allowing variations in inhalation depth and duration as the only available compensatory strategy, the experimenter might be able to measure smokers' attempts to regulate nicotine intake along one dimension (assuming that inhalation depth and duration are measured with strain gauges).

By preserving the natural participation of the subject while taking each puff, our device provides a useful way to study the role of oral factors in smoking satisfaction while controlling the nicotine dose delivered to the subject.

\section{REFERENCES}

ADAms, P. I. (1978). The influence of cigarette smoke yield on smoking habits. In R. E. Thorton (Ed.), Smoking behavior: Physiological and psychological influences (pp. 349-360). London: ChurchillLivingstone.

Behm, F. M., Levin, E. D., LeE, Y. K., Rose, J. E. (1989). Lownicotine regenerated smoke aerosol reduces desire for cigarettes. Manuscript submitted for publication.

Creighton, D. E., Lewis, P. H. (1978). The effect of different cigarettes on human smoking patterns. In R. E. Thorton (Ed.), Smoking behavior: Physiological and psychological influences (pp. 76-86). London: Churchill-Livingstone. 
DunN, P. J. (1978). The effects of reduced draw resistance on human smoking parameters and alveolar carbon monoxide levels. In R. E. Thorton (Ed.), Smoking behavior: Physiological and psychological influences (pp. 195-202). London: Churchill-Livingstone.

Gilbert, D. G., Jensen, R. A., \& Meliska, C. J. (1988). A system for administering quantified doses of tobacco smoke to human subjects: Plasma nicotine and filter pad validation. Pharmacology, Biochemistry \& Behavior, 31, 905-908.

Gust, S. W., \& PiCKens, R. W. (1982). Does cigarette nicotine yield affect puff volume? Clinical Pharmacology \& Therapeutics, 32, 418-422.

Gust, S. W., Pickens, R. W., \& Pechacek, T. F. (1983). Recording puff volume in smoking. Behavior Research Methods \& Instrumentation, 15, 341-343.

Henningfield, J. E., \& Griffiths, R. (1980). Effects of ventilated cigarette holders on cigarette smoking in humans. Psychopharmacology, 68, 115-119.

Herning, R. I., Jones, R. T., Bachman, J., \& Mines, A. H. (1981). Puff volume increases when low nicotine cigarettes are smoked. British Medical Journal, 283, 187-189.

Herning, R. I., Jones, R. T., Benowitz, N. L., \& Mines, A. H. (1983). How a cigarette is smoked determines blood nicotine levels. Clinical Pharmacology \& Therapeutics, 33, 84-90.

Pomerleau, O. F., Rose, J. E., Pomerleau, C. S., \& Majchrzak, M. J. (1989). A noninvasive method for delivering controlled doses of nicotine via cigarette smoke. Manuscript submitted for publication.

RAABE, O. G. (1980). Physical properties of aerosols affecting inhalation toxicology. In C. L. Sanders, F. T. Cross, G. E. Dayle, \& J. A. Mahaffey (Eds.), Pulmonary toxicology of respirable particles (pp. 128). Oak Ridge, TN: Technical Information Center, U.S. Department of Energy.
Rawbone, R. G. (1981). Puff volume increases when low nicotine cigarettes are smoked. British Medical Journal, 283, 498.

Rawbone, R. G., Murphy, K., TAte, M. E., \& Kane, S. J. (1978). The analysis of smoking parameters, inhalation and absorption of tobacco smoke in studies of human smoking behavior. In R. E. Thorton (Ed.), Smoking behavior: Physiological and psychological influences (pp. 171-194). London: Churchill-Livingstone.

ROSE, J. E., \& BEHM, F. (1987). Refined cigarette smoke as a method for reducing nicotine intake. Pharmacology, Biochemistry \& Behavior, 28, 305-310.

Rose, J. E., \& Hickman, C. (1987). Citric acid aerosol as a potential smoking cessation aid. Chest, 92, 1005-1008.

Rose, J. E., Tashinin, D. P., ErTle, A., Zinzer, M. C., Lafer, R. (1985). Sensory blockade of smoking satisfaction. Pharmacology, Biochemistry \& Behavior, 23, 289-293.

STEPNEY, R. (1980). Consumption of cigarettes of reduced tar and nicotine delivery. British Journal of Addiction, 75, 81-88.

Sutton, S. R., Feyerbend, C., Cole, P. V., Russell, M. A. H. (1978). Adjustment of smokers to dilution of tobacco smoke by ventilation cigarette holders. Clinical Pharmacology \& Therapeutics, 24, 395-405.

Wu, T. C., Tashkin, D. P., Duahed, B., \& Rose, J. E. (1988). Pulmonary hazards of smoking Marijuana as compared with tobacco. New England Journal of Medicine, 318, 347-351.

ZaCnY, J. P., Stitzer, M. L., Brown, F. J., Yingling, J. E., \& GrifFiths, R. G. (1987). Human cigarette smoking: Effects of puff and inhalation parameters on smoke exposure. Journal of Pharmacology \& Experimental Therapeutics, 240, 554-564.

(Manuscript received November 30, 1988; revision accepted for publication February 21, 1989.) 